\title{
G

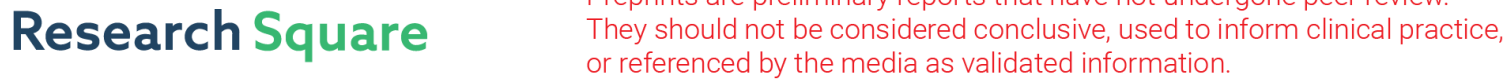 \\ Feasibility of dpFAMM flap in Tongue \\ Reconstruction After Facial Vessels Ligation and Radiotherapy- Case Presentation
}

Gontarz Michał ( $\sim$ mgontarz@op.pl )

Jagiellonian University Medical College Faculty of Medicine: Uniwersytet Jagiellonski Collegium Medicum Wydzial Lekarski https://orcid.org/0000-0002-8180-948X

\section{Jakub Bargiel}

Jagiellonian University in Krakow Medical College Faculty of Medicine: Uniwersytet Jagiellonski w

Krakowie Wydzial Lekarski

\section{Krzysztof Gąsiorowski}

Jagiellonian University in Krakow Medical College Faculty of Medicine: Uniwersytet Jagiellonski w Krakowie Wydzial Lekarski

\section{Tomasz Marecik}

Jagiellonian University in Krakow Medical College Faculty of Medicine: Uniwersytet Jagiellonski w Krakowie Wydzial Lekarski

\section{Paweł Szczurowski}

Jagiellonian University in Krakow Medical College Faculty of Medicine: Uniwersytet Jagiellonski w Krakowie Wydzial Lekarski

\section{Jan Zapała}

Jagiellonian University in Krakow Medical College Faculty of Medicine: Uniwersytet Jagiellonski w

Krakowie Wydzial Lekarski

\section{Grażyna Wyszyńska-Pawelec}

Jagiellonian University in Krakow Medical College Faculty of Medicine: Uniwersytet Jagiellonski w Krakowie Wydzial Lekarski

\section{Case report}

Keywords: FAMM flap, facial artery musculomucosal flap, Bozola flap, tongue cancer, reconstruction, salvage surgery, buccinator myomucosal flap, tongue reconstruction, tongue squamous cell carcinoma, dpFAMM flap

Posted Date: November 8th, 2021

DOI: https://doi.org/10.21203/rs.3.rs-1039084/v1 
License: (c) (i) This work is licensed under a Creative Commons Attribution 4.0 International License. Read Full License 


\section{Abstract}

\section{Background}

Salvage surgery with reconstruction of the second and next primary tongue cancer remains difficult, especially after earlier neck dissection and radiotherapy. In the current report, we describe the feasibility of the extended, double-pedicled facial artery musculomucosal (dpFAMM) flap in the reconstruction of the patient with second primary tongue squamous cell carcinoma, after facial vessels ligation and radiotherapy.

\section{Case presentation}

81-year-old female patient was operated on due to tongue squamous cell carcinoma (SCC) on the left side T3N1M0 in 2019. Bilateral selective neck dissection with tongue reconstruction was performed by island FAMM flap. The patient also suffered from synchronous mucinous breast carcinoma treated with tamoxifen. Second primary SCC of the tongue on the opposite (right) side was detected in 2020. The patient did not agree for surgical treatment therefore radiotherapy was performed. Local recurrence of the tongue cancer of the right side was treated surgically in 2021. Salvage surgery comprised hemiglossectomy and dpFAMM flap reconstruction with uneventful postoperative follow-up.

\section{Conclusions}

This case presentation proved that dpFAMM flap can be used in salvage surgery and reconstruction even in patients after ligation of facial vassels, irradiation and in the course of hormone therapy. The flap is easy to handle, has good vascularity and comprises predictable method of reconstruction, especially for patients with severe comorbidities.

\section{Background}

The incidence of synchronous and metachronous second oral cancer is increasing due to longer lifespan and improvement of oncological therapy [1]. However, surgical treatment and reconstruction of second and next primary cancer in the oral cavity remains difficult, especially after previous neck dissection and radiotherapy. Defects of the tongue might be reconstructed by local flaps, such as the facial artery musculomucosal (FAMM) flap and its modifications [2-7]. The FAMM flap is an axial flap based on the facial artery and is useless in case of facial vessels ligation. In such cases the reconstruction should be converted to Bozola flap [8]. Extended, double-pedicled FAMM (dpFAMM) flap is own modification of FAMM flap with facial and buccal vessels blood supple [3].

In the current report, we describe the feasibility of the dpFAMM flap in the reconstruction in the patient with second primary tongue squamous cell carcinoma, after facial vessels ligation and radiotherapy.

\section{Case Presentation}


In November 2019, an 81-year-old female patient was admitted to our Department due to tongue squamous cell carcinoma (SCC) on the left side T3N1M0. Clinical and radiological examination revealed synchronous left breast tumor (Fig. 1). Biopsy from the breast tumor revealed mucinous carcinoma and diagnostic imaging excluded dissemination. After tumor board consultation, we decided to start the treatment with surgical excision of tongue SCC and bilateral neck dissection. Selective bilateral neck dissection (levels I-IV ipsilateral and I-III contralateral) was performed by a horizontal neck fold incision. During neck dissection, facial vessels on the left side were preserved for an island FAMM (iFAMM) flap. However, facial vessels on the right side were ligated. Tongue cancer was excised with margins control by frozen section examination. Tongue reconstruction with iFAMM flap was performed according to the technique described by Joseph et al. (Fig. 2-4) [4]. The healing process was uneventful. Histopathological examination revealed squamous cell carcinoma G1 resected with inadequate distal margin $(2 \mathrm{~mm})$ and metastasis in one lymph node (lla cervical level) on the left side. The patient was qualified to postoperative radiotherapy and radical mastectomy with axillary nodes dissection. However, the patient did not give her consent for the proposed treatment.

In February 2020, the patient started hormone therapy with tamoxifen due to breast cancer and had oncological controls in our outpatient department every month. In December 2020, after four months from the last visit, the patient was admitted to the outpatient clinic with suspicion of tongue cancer on the opposite, right side. Biopsy from the ulceration confirmed SCC G2. Clinical and radiological examination revealed only local advancement of the disease. Breast cancer disease was stable. We proposed surgical treatment, but the patient again did not give her consent. For that reason, the patient was qualified to definitive radiotherapy. However, the total dose was reduced due to general health condition. The patient received $30 \mathrm{~Gy}$ in 10 fractions on the second primary and cervical region and the treatment was finished in February 2021. In May 2021, two months after the last visit, the patient was admitted to our outpatient department with dysphagia and odynophagia. Clinical examination and biopsy confirmed local recurrence of the tongue cancer on the right side. Computer tomography (CT) showed local recurrence with dimensions $21 \times 42 \times 29 \mathrm{~mm}$ and without suspicious neck lymph nodes (Fig. 5,6). Definitive radiotherapy was impossible at this stage of the disease. The patients agreed to salvage surgery, hemiglossectomy with reconstruction and without neck dissection. Due to the fact that right facial vessels were ligated in November 2019 and considering the extent of the defect, iFAMM was not possible. Also general condition of the patient was a contraindication to extensive, long procedure such as free flap reconstruction. Another contraindication for free flap reconstruction was higher risk of early postoperative thrombosis of microvascular anastomoses due to continuous tamoxifen intake. Based on CT evaluation, we decided to use dpFAMM flap for reconstruction, which was performed as described earlier (Fig. 7,8) [3]. The healing process was uneventful (Fig. 9). Unfortunately, in August 2021 we observed enlarged cervical lymph nodes on the left side. Neck dissection in levels II and $\mathrm{V}$ was performed. Histopathological examination confirmed three metastatic lymph nodes. The patient was disqualified from adjuvant radiotherapy and chemotherapy. The patient died 2 months following neck dissection due to pneumonia. 


\section{Discussion And Conclusions}

Soft tissue defects of the oral cavity are challenging in the reconstructive surgery due to loss of motility, secretion and sensory functions of mucous membrane. Reconstruction especially of tongue defects should ensure proper patient's speech and swallowing. Skin grafts are ineffective in the case of bone exposure and have a tendency to keratinization and cicatrization, which additionally decreases the movability of the remaining, healthy oral mucosa [8]. Also most pedicled regional and free flaps containing skin island are characterized by impaired sensitivity, keratinization, hair growth and donor site morbidity. Local musculomucosal flaps are a good method of reconstruction of moderate tongue defects [3]. According to Massarelli et al. [8] all buccinator musculomucosal flaps provide proper mucus secretion and sensitivity without shrinking tendency, especially after radiotherapy.

The iFAMM flap in the tongue reconstruction is possible in case of facial vessels preservation. Massarelli et al. [8] suggest that iFAMM flap pedicled solely on the facial artery with the surrounding fat tissue provides the correct venous drainage, without flap congestion. However, Rahpeyma et al. [9] in experimental studies on dogs observed iFAMM flap loss in each case of facial vein ligation. For that reason, iFAMM flap, pedicled only on facial artery, is not acceptable for clinical usage [9]. In our case, the patient had facial vein and artery ligated during neck dissection 18 months earlier. This was the main contraindication for tongue reconstruction by iFAMM. However, the vascularization of the buccinator muscle is derived from the branches of facial vessels in anterior part and buccal vessels in posterior region. Due to the fact, that CT revealed preserved distal part of the facial artery in buccal region (Fig. 5) and a large number of anastomoses between facial and buccal angiosome, which ensures good blood supply through buccal vessels, we decided to used dpFAMM flap for this reconstruction [8]. The dpFAMM flap combines the advantages of both the FAMM and the Bozola flap, which allows its extension to be increased with sufficient venous drainage [3].

Another issue concerning reconstruction is preoperative radiotherapy. It should be pointed out that both the donor and recipient sites comprise the irradiation field, which implies a higher risk of healing process problems with potential flap necrosis. O'Leary and Bundgaard [10] suggested that FAMM flap is not suitable in patients, who underwent previous radiotherapy, due to the risk of such complications as trismus, bleeding, osteoradionecrosis and impaired healing followed by flap necrosis. They observed partial flap necrosis in 75\% (3 from 4 patients) of cases. On the other hand, Ayad et al. [11] did not notice the specific complication rate in group of 10 patients previously irradiated. In our case, we also did not detect problems with healing, bleeding and proper mouth opening. Short term of the follow up did not allow for evaluation of possible mandibular osteoradionecrosis.

Healing process can also be disturbed by hormone therapy. According to Billon et al. [12] hormone therapy, including tamoxifen intake, seems to be associated with a higher risk of postoperative wound healing complications in patients with breast reconstruction. In addition, Parikh et al. [13] in their metaanalysis concluded that perioperative tamoxifen therapy may increase the risk of thrombotic flap complications and flap loss in patients undergoing free flap reconstruction due to breast cancer. They 
suggested that short cessation of the tamoxifen therapy, about 4 weeks prior to reconstructive treatment, might decrease the risk of complications [13]. Our patient also suffered from synchronous mucinous carcinoma of the left breast treated with tamoxifen since 15 months before salvage surgery. This was one of the contraindication for free radial forearm flap application and choice of dpFAMM flap for tongue reconstruction. Transient discontinuation of tamoxifen before surgery was not recommend. However, healing process was uneventful.

Extension of the dpFAMM flap in the anterior part of the buccinator muscle provided ability for tongue reconstruction, even after hemiglossectomy. If the apex of the tongue can be preserved during ablative surgery, like in this case, dpFAMM flap can be doubled. Preserved apex of the tongue is rotated backward to obtain best clinical result of the reconstruction. Flap's harvesting takes around 30-50 minutes and can be done by one surgical team. The dpFAMM flap has a perfect color and structure, matching the surrounding tissues without additional extraoral scars. This case presentation proved that dpFAMM flap can be used for reconstruction in salvage surgery, even, if facial vassels had been ligated previously and the patient was irradiated and treated with hormone therapy. Other advantages of the dpFAMM flap include its feasibility in the reconstruction of other areas, like the floor of the mouth, the alveolar ridge, the soft and hard palates, or the oropharynx.

\section{Abbreviations}

FAMM

facial artery musculomucosal flap

dpFAMM

double-pedicled facial artery musculomucosal flap

iFAMM

island facial artery musculomucosal flap

SCC

squamous cell carcinoma

CT

computer tomography

\section{Declarations}

\section{Acknowledgements}

We thank dr Krzysztof Śliwiński for technical assistance in clinical imaging.

\section{Authors' contributions}

MG and GWP designed the study and drafted the manuscript. MG, JB and KG reviewed this case presentation and checked the patient's treatments. MG, TM, PS and JZ analyzed the data and provided 
the clinical image and information. MG, JZ and GWP developed the concept and edited the paper. All authors have read and approved the final manuscript.

\section{Funding}

None.

\section{Availability of data and materials}

All data during the study are included within the article.

\section{Ethics approval and consent to participate}

Written informed consent was obtained from the patient prior to submission of the case report. The study was conducted according to the guidelines of the Declaration of Helsinki and approved by the Institutional Review Board of the Jagiellonian University (No: 1072.6120.229.2021, date of approval 29.09.2021).

\section{Consent for publication}

The patient has given her consent for the case report to be published.

\section{Competing interests}

The authors declare that they have no competing interests.

\section{Author details}

${ }^{1}$ Department of Cranio-Maxillofacial Surgery, Jagiellonian University Medical College, Cracow, Poland

\section{References}

1. Qaisi M, Vorrasi J, Lubek J, Ord R. Multiple primary squamous cell carcinomas of the oral cavity. J Oral Maxillofac Surg. 2014;72(8):1511-6. doi: 10.1016/j.joms.2014.03.012.

2. Duranceau M, Ayad T. The facial artery musculomucosal flap: Modification of the harvesting technique for a single-stage procedure. Laryngoscope 2011;121:2586-89.

3. Gontarz M, Bargiel J, Gąsiorowski K, Marecik T, Szczurowski P, Zapała J, et. al. Extended, DoublePedicled Facial Artery Musculomucosal (dpFAMM) Flap in Tongue Reconstruction in Edentulous Patients: Preliminary Report and Flap Design. Medicina (Kaunas). 2021;26;57(8):758. doi: 10.3390/medicina57080758.

4. Joseph ST, Naveen BS, Mohan TM. Islanded facial artery musculomucosal flap for tongue reconstruction. Int. J. Oral Maxillofac. Surg. 2017;46:453-55. 
5. Zhao Z, Zhang Z, Li Y, Li S, Xiao S, Fan X, et al. The buccinator musculomucosal island flap for partial tongue reconstruction. J Am Coll Surg. 2003;196:753-60.

6. Massarelli O, Gobbi R, Raho MT, Tullio A. Three-dimensional primary reconstruction of anterior mouth floor and ventral tongue using the 'trilobed' buccinator myomucosal island flap. Int J Oral Maxillofac Surg. 2008;37(10):917-22. doi: 10.1016/j.ijom.2008.07.020.

7. Massarelli 0 , Gobbi R, Soma D, Tullio A. The folded tunnelized-facial artery myomucosal island flap: a new technique for total soft palate reconstruction. J Oral Maxillofac Surg. 2013;71(1):192-8. doi: 10.1016/j.joms.2012.03.030.

8. Massarelli O, Baj A, Gobbi R, Soma D, Marelli S, De Riu G, et al. Cheek mucosa: a versatile donor site of myomucosal flaps. Technical and functional considerations. Head Neck. 2013;35(1):109-17. doi: 10.1002/hed.22933.

9. Rahpeyma A, Khajehahmadi S, Sedigh HS. Facial Artery Myomucosal Flap, Pedicled Solely on the Facial Artery: Experimental Design Study on Survival. J Craniofac Surg. 2016;27(7):e614-e615. doi: $10.1097 /$ SCS. 0000000000002947.

10. O'Leary P, Bundgaard T. Good results in patients with defects after intraoral tumour excision using facial artery musculo-mucosal flap. Dan Med Bull. 2011;58(5):A4264.

11. Ayad T, Kolb F, De Monés E, Mamelle G, Temam S. Reconstruction of floor of mouth defects by the facial artery musculo-mucosal flap following cancer ablation. Head Neck. 2008;30(4):437-45. doi: 10.1002/hed.20722.

12. Billon R, Bosc R, Belkacemi Y, Assaf E, SidAhmed-Mezi M, Hersant B, et al. Impact of adjuvant antiestrogen therapies (tamoxifen and aromatase inhibitors) on perioperative outcomes of breast reconstruction. J Plast Reconstr Aesthet Surg. 2017;70(11):1495-1504. doi: 10.1016/j.bjps.2017.05.046.

13. Parikh RP, Odom EB, Yu L, Colditz GA, Myckatyn TM. Complications and thromboembolic events associated with tamoxifen therapy in patients with breast cancer undergoing microvascular breast reconstruction: a systematic review and meta-analysis. Breast Cancer Res Treat. 2017;163(1):1-10. doi: 10.1007/s10549-017-4146-3.

\section{Figures}




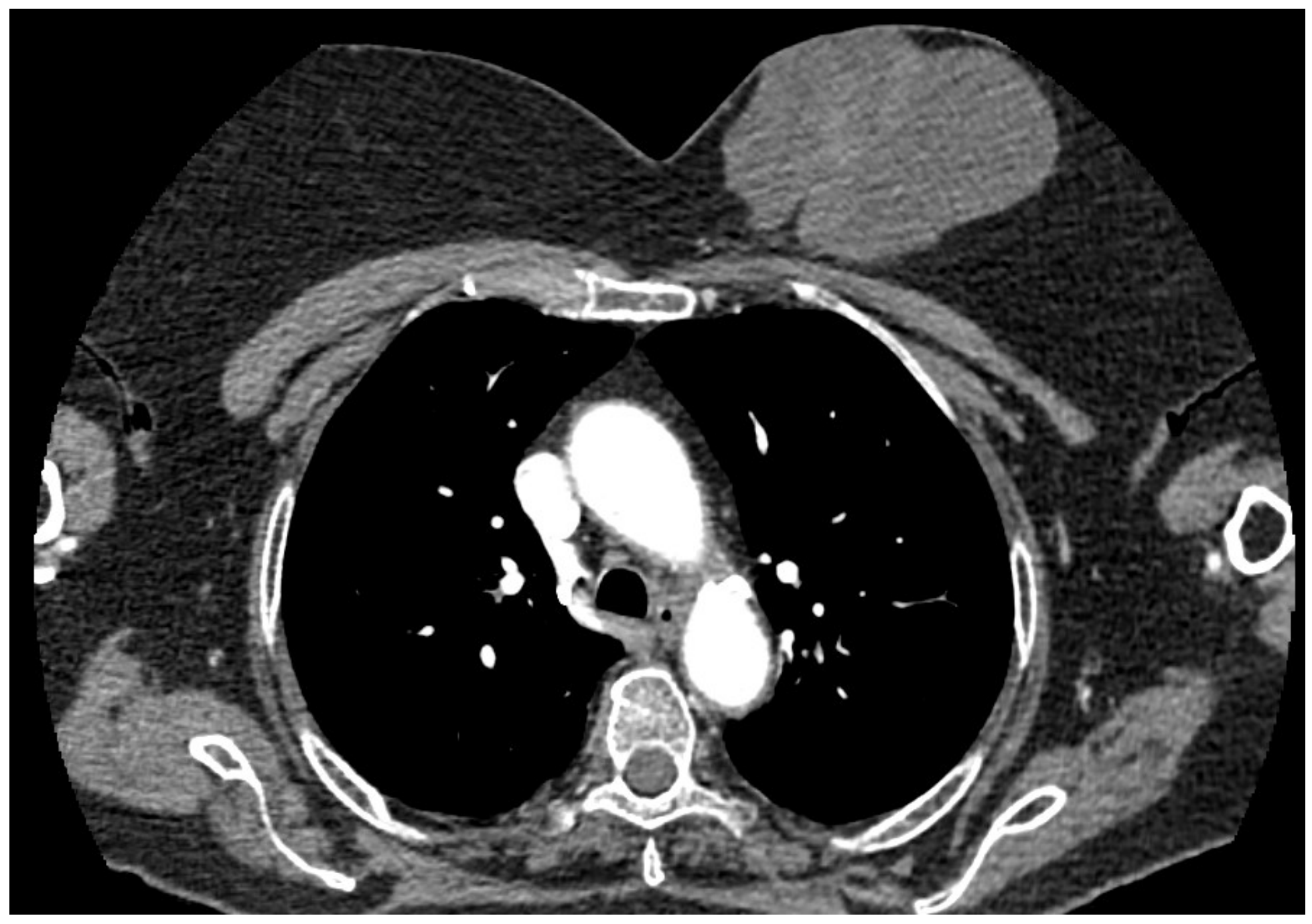

Figure 1

CT axial view of the chest showing huge breast cancer on the left side. 


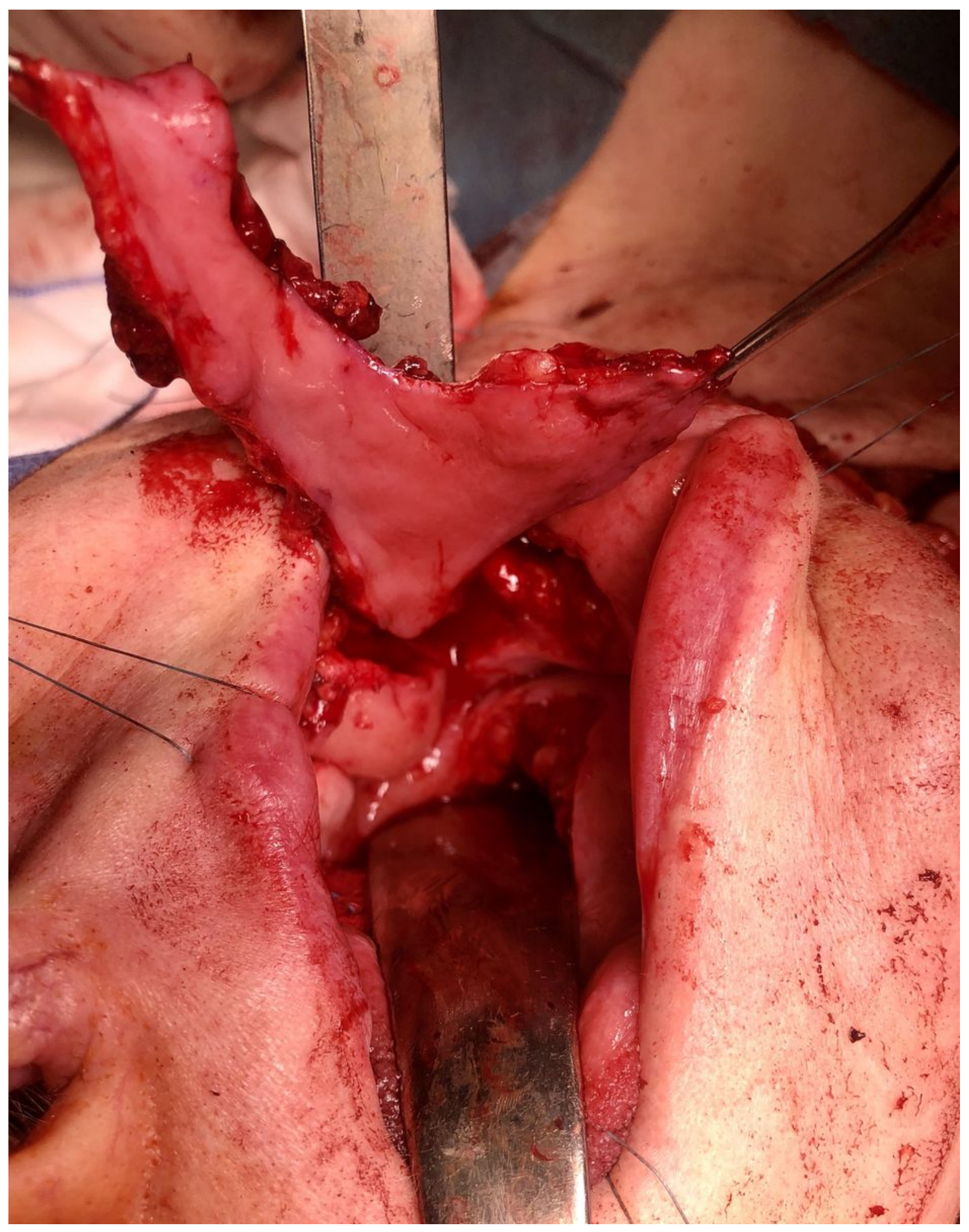

Figure 2

The harvested trilobed iFAMM flap. 


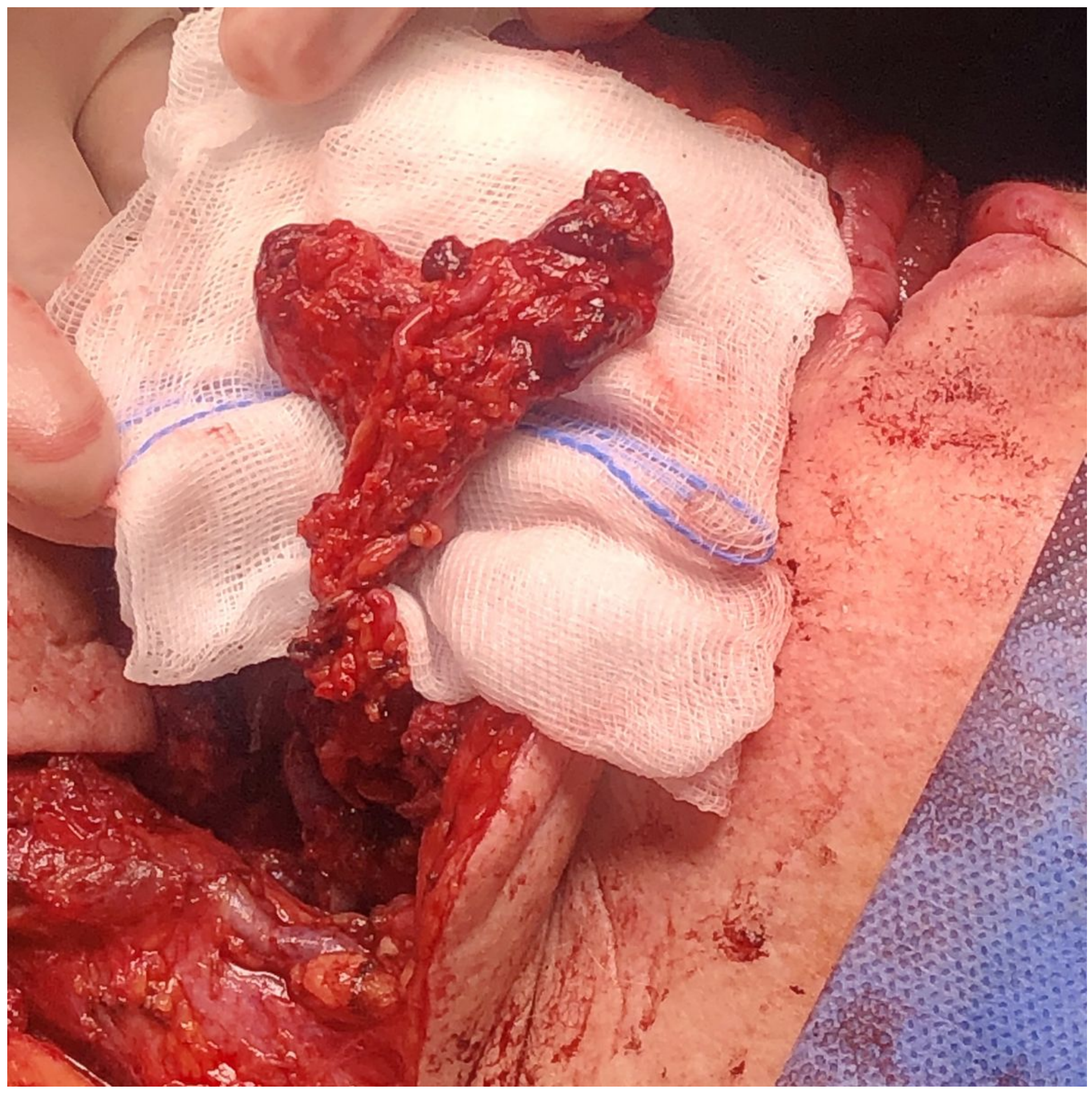

Figure 3

Transposition of the iFAMM flap with facial vessels pedicle over the mandible. 


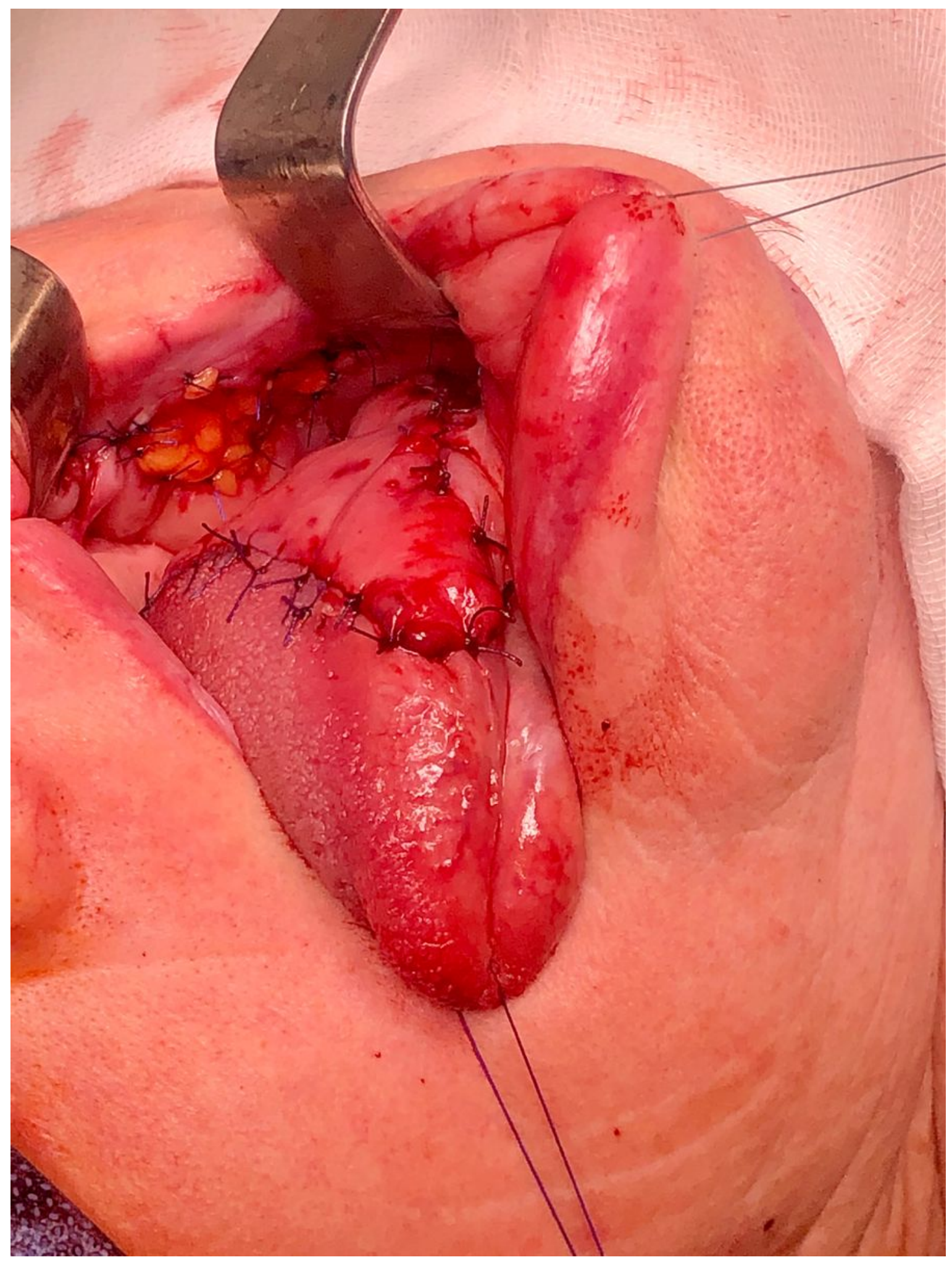

Figure 4

Immediate postoperative result of tongue reconstruction with iFAMM flap.

原

Figure 5 
CT with 3D reconstruction showing stump of ligated facial artery on the right side (blue arrow), preserved buccal artery on the right side (green arrow) and absence of facial vessels after iFAMM harvesting on the left side (red arrow).

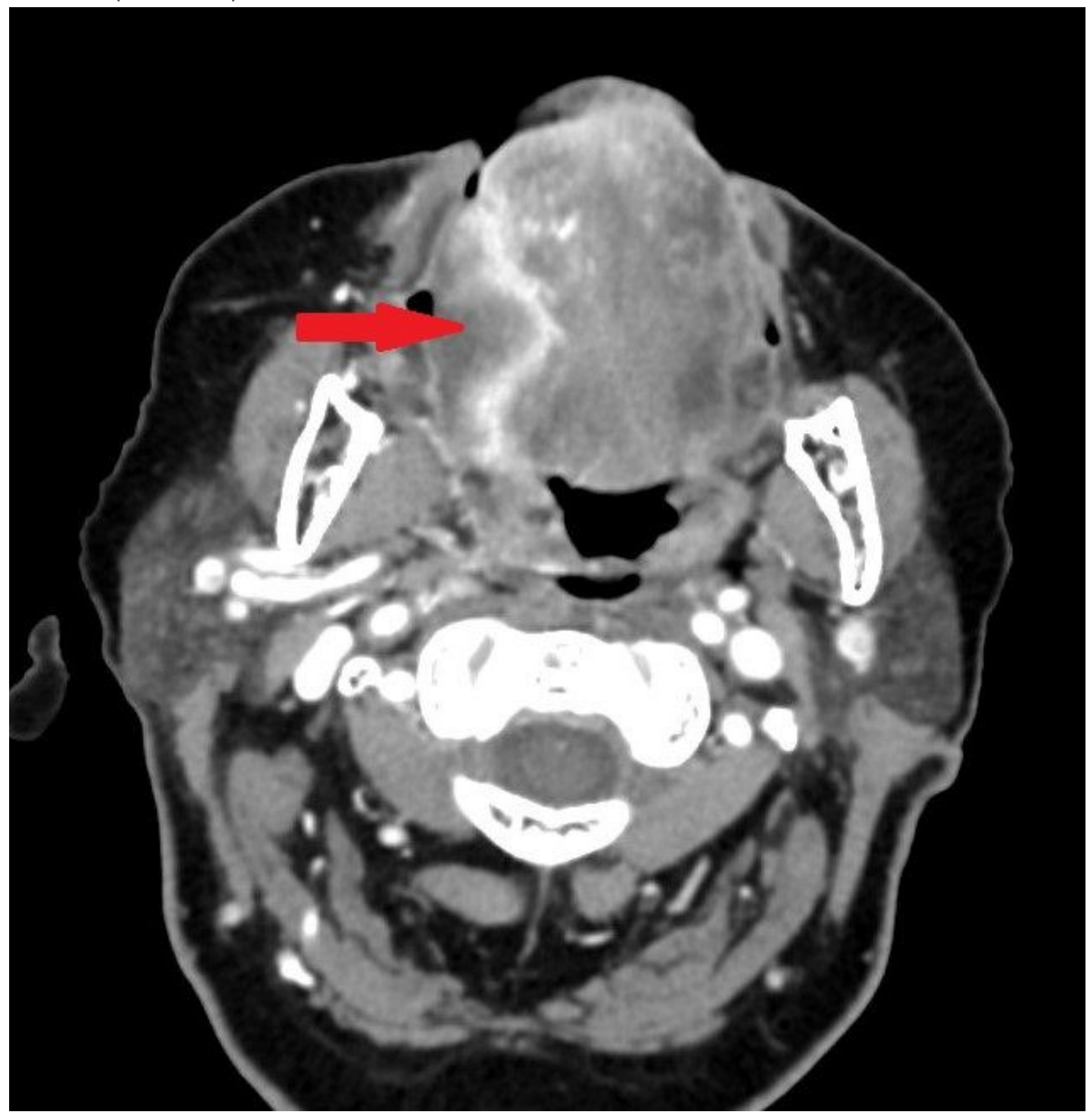

Figure 6

CT axial view of extensive local recurrence after definitive radiotherapy of the tongue SCC on the right side (red arrow). 


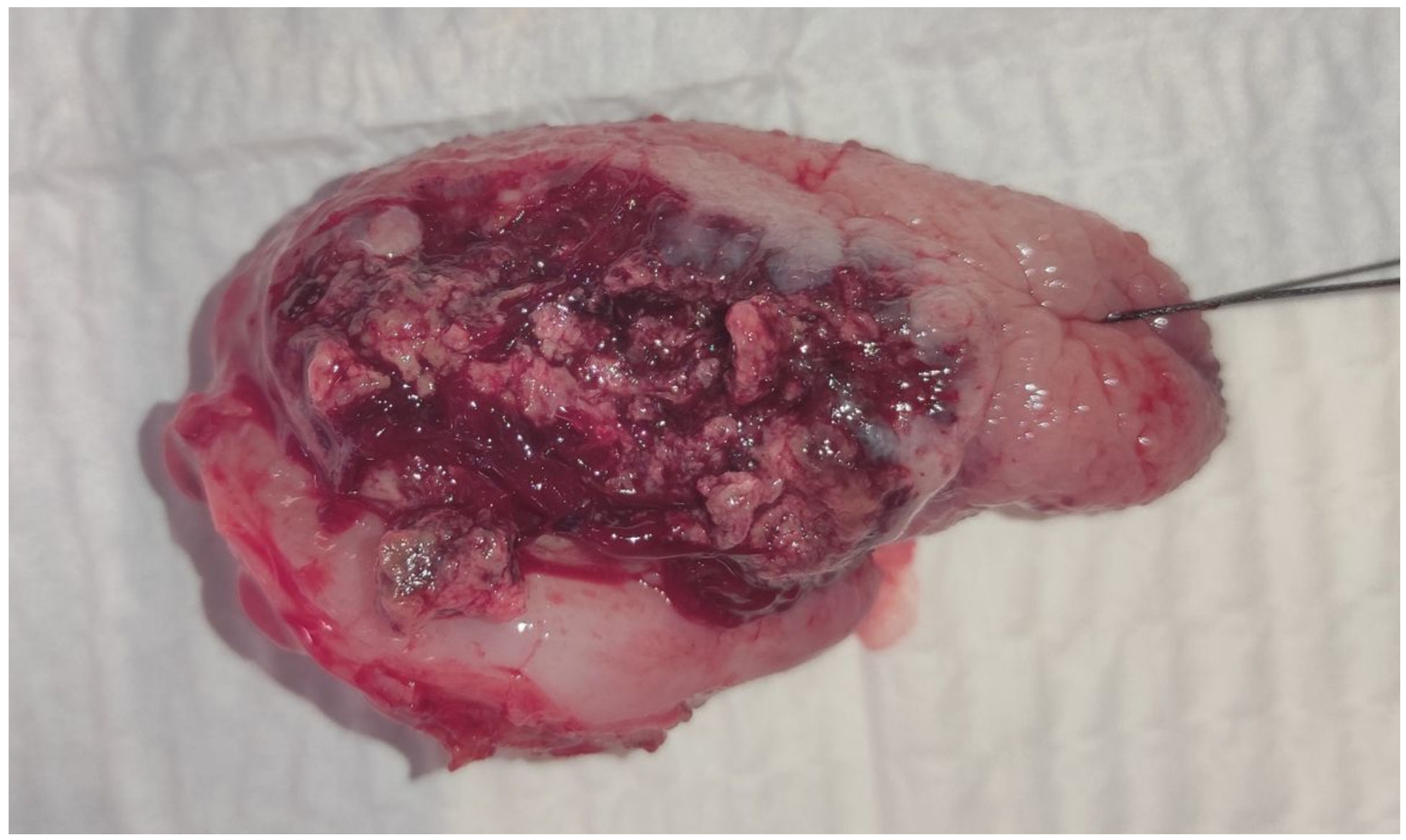

Figure 7

Salvage surgery. Surgical specimen of the tongue after right hemiglossectomy. 


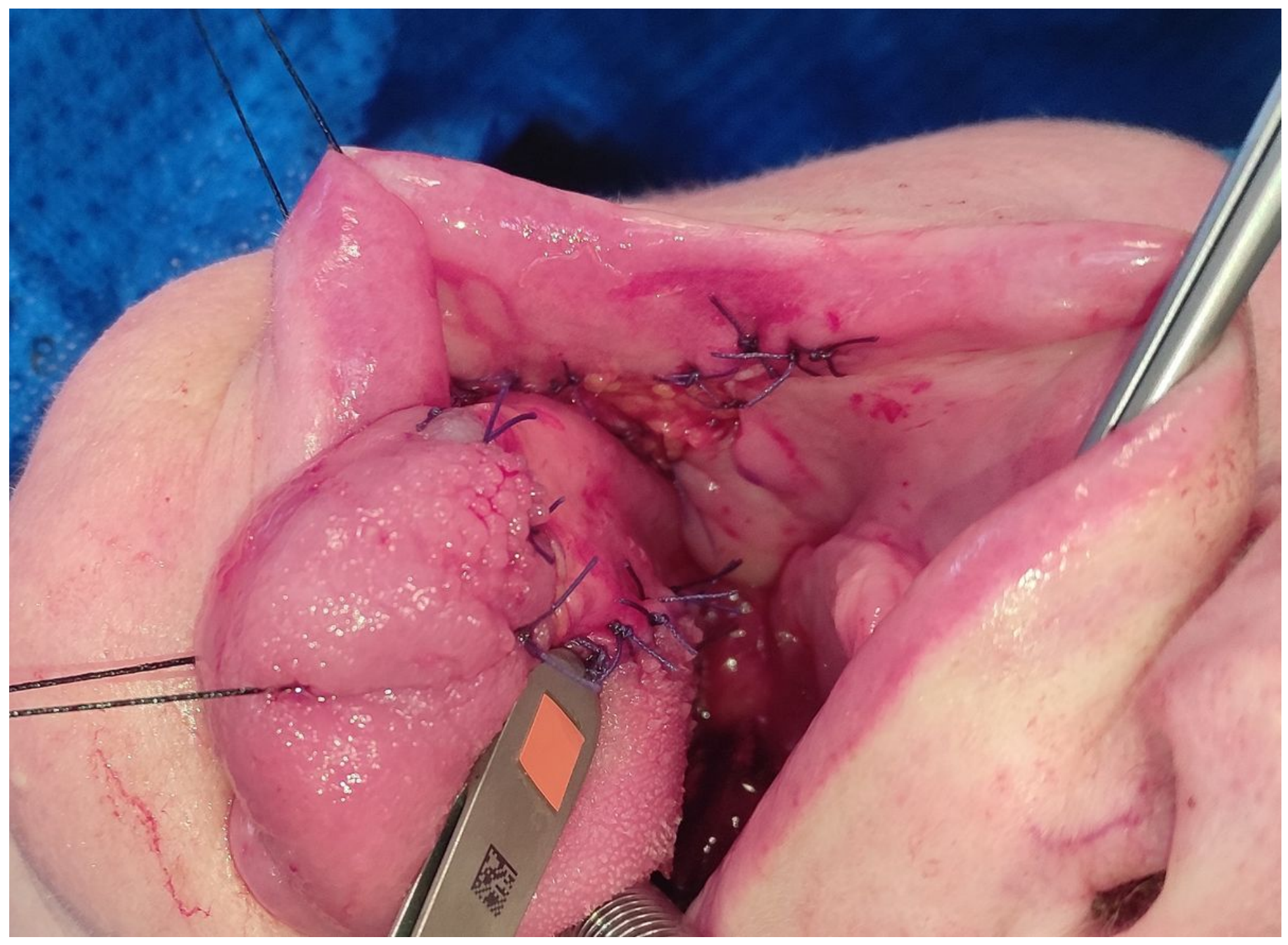

Figure 8

Immediate postoperative result of tongue reconstruction with dpFAMM flap. 


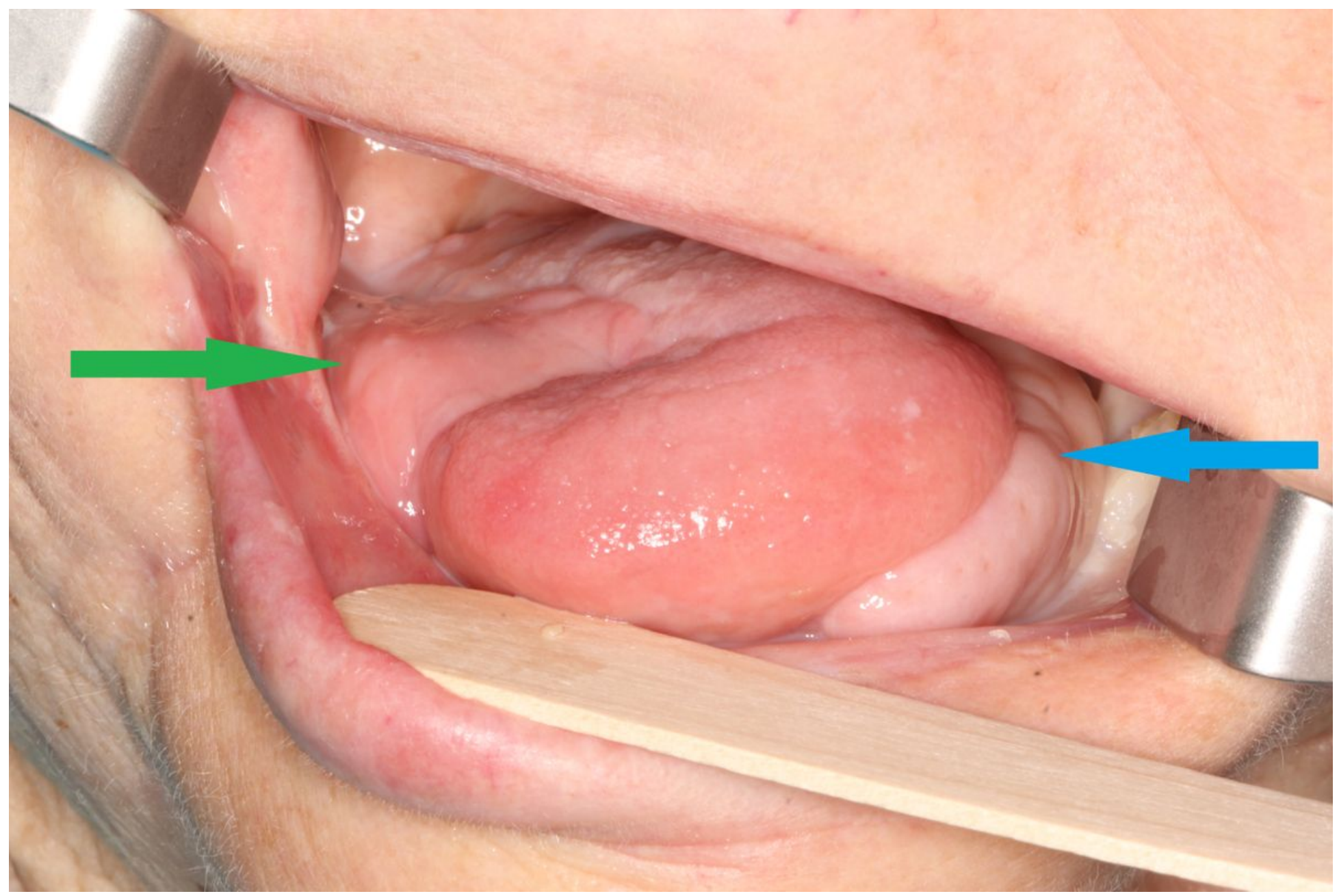

\section{Figure 9}

Final result. 3 months after tongue reconstruction with dpFAMM flap (green arrow) and iFAMM flap (blue arrow- 21 months after surgery). 